\title{
TO STUDY THE THYROID PROFILE IN POSTPARTUM PERIOD “A PROSPECTIVE STUDY”
}

\author{
Sandhya Gautam ${ }^{1}$, Shweta Sharma², Dhanveer Singh ${ }^{3}$, Urmila Karya ${ }^{4}$ \\ ${ }^{1}$ Assistant Professor, Department of Medicine, LLRM MC, Meerut. \\ ${ }^{2}$ Assistant Professor, Department of Medicine, LLRM MC, Meerut. \\ ${ }^{3}$ Assistant Professor, Department of Medicine, Subharti Medical College, Meerut. \\ 4 Professor, Department of Obstetrics and Gynaecology, LLRM MC, Meerut.
}

ABSTRACT
BACKGROUND
A healthy and well-functioning thyroid gland is important to everyone, but it is especially important to a woman in their child
bearing age. Postpartum thyroiditis is a syndrome of transient or permanent thyroid dysfunction occurring in the first year after
delivery and based on autoimmune inflammation of thyroid gland.(1,2)

\section{AIMS AND OBJECTIVES}

1. To determine the prevalence of thyroid dysfunction in postpartum period.

2. To see the prevalence of TPOab in the postpartum thyroiditis.

3. Percentage of recovery normal thyroid function after postpartum period.

\section{MATERIAL AND METHOD}

This study was carried out in the Department of Medicine and Obstetrics and Gynaecology Department of L.L.R.M Medical College, Meerut, from May 2013 to May 2014; 100 women of postpartum period was selected from OPD and Wards and subjected to a protocol which include history specially palpitation, depression, fatigue, sweating, constipation and examination with a special reference to general body built, height, weight, pulse, BP, respiratory rate, pallor, cyanosis, icterus, oedema, lymphadenopathy, body temperature, eyes signs, hairs and skin changes and BMR were noted. All the system were examined thoroughly.

Thyroid gland was examined thoroughly. All the women are subjected to following investigation. A complete haemogram T3, T4, TSH, TPO antibodies and blood sugar (Fasting and PP). All were followed at 6 weeks and 6 months with above protocol.

\section{RESULT}

The study groups consist of 100 women of post-partum period, (06 weeks to 06 months) with no previous history of thyroid disorder. All subjects were randomly selected. Most of the women were between age group of 20 to 25 years of age, approximately $45 \%$ of the study group. Most of the women were parity of (1-2) and (2-3). Out of 100 women, 11 women showed postpartum thyroid dysfunction (Approximately 11\%); 06 women were hyperthyroid having thyroid value between 21.9-29.0 and TSH between 0.005-0.350. Two women show subclinical hypothyroidism (Normal T3, T4 and high TSH). Three women were hypothyroid (Decrease T3 and T4, increase TSH). All women were followed with OPD, phone and home visit at 6 months. Out of 11 women who were previously showing postpartum thyroid dysfunction, one women showed complete recovery which was previously hyperthyroid. Out of 6 hyperthyroid 2 became hypo, 1 became euthyroid and 3 remained hyper at 6 months. Out of 5 hypothyroid, 1 became euthyroid, 4 remained hypothyroid. Thus at the end of study, approximately $9 \%$ women were having thyroid dysfunction. In this study, 8 women were having positive TPOAb, in which 5 women were showing thyroid dysfunction and 3 women who were positive did not show postpartum thyroid dysfunction. Thus in TPOAb positive women prevalence was app. $62 \%$. In this study 4 women were having gestational diabetes, out of which 1 woman also had postpartum thyroid dysfunction. There is also increase in depressive symptoms in this group (TPOAb positive).

\section{CONCLUSION}

Postpartum thyroiditis is significantly present in women of postpartum period, which usually goes undiagnosed. It shows a strong correlation with TPOab, gestational diabetes mellitus and depression.

\section{KEYWORDS}

Postpartum, Hyperthyroid, Hypothyroid, T3, T4, TSH, TPO Antibodies, Diabetes Mellitus.

HOW TO CITE THIS ARTICLE: Gautam S, Sharma S, Singh D, et al. To study the thyroid profile in postpartum period "a prospective study." J. Evolution Med. Dent. Sci. 2016;5(33):1786-1789, DOI: 10.14260/jemds/2016/421

\section{INTRODUCTION}

Many new mothers complain of exhaustion and fatigue well after delivery and within a few weeks of postpartum.

Financial or Other, Competing Interest: None.

Submission 06-02-2016, Peer Review 07-03-2016,

Acceptance 12-03-2016, Published 22-04-2016.

Corresponding Author:

Dr. Sandhya Gautam,

R 21, Medical College Campus, LLRM MC,

Meerut-250004, Uttar Pradesh.

E-mail: sandyg.3080@gmail.com

DOI: $10.14260 /$ jemds $/ 2016 / 421$
This can be related to unexpected stress of caring for a new born, lack of sleep, in some cases a medical condition involving dysfunction of thyroid gland called as postpartum thyroid dysfunction. Postpartum thyroid disorder is a syndrome of transient or permanent thyroid dysfunction occurring in the first year after delivery and based on autoimmune inflammation of thyroid gland. $(3,4)$

A healthy and well-functioning thyroid gland is important to everyone, but it is especially important to woman of child bearing age group; the presence of anti- 
thyroid antibodies can further complicate the woman's health.

In addition to increasing risk of developing postpartum thyroiditis, the presence of anti-thyroid antibodies has been linked to increased incidence of infertility, miscarriage.(5) and postpartum depression.(6) Early detection shorten the duration and extent of suffering of a woman.

\section{A Postpartum Thyroid Disorder usually follows Three Courses. $(7,8)$}

- A hyperthyroid phase followed by return to normal thyroid function.

- A hypothyroid phase.

- A hyperthyroid phase followed by a hypothyroid phase.

\section{AIMS AND OBJECTIVES}

- To determine the prevalence of thyroid dysfunction in postpartum period.

- To see the prevalence of TPOab in the postpartum thyroiditis.

- Percentage of recovery to normal thyroid function after postpartum period.

\section{MATERIAL AND METHOD}

This prospective study was conducted at Department of Medicine and Obstetrics and Gynaecology, L.L.R.M Medical College, Meerut, from May 2013 to May 2014.

- 100 women of postpartum period (6 wks. to 6 months) was randomly selected from OPD and Wards with no previous history of thyroid disorder.

- Inclusion criteria includes women of age group between 20-45 years, postpartum period from 6 wks. to 6 months, history of postpartum dysfunction in previous delivery, women having strong family history of autoimmune thyroid disease.

\section{All are subjected to a Protocol which Include}

- History regarding symptoms such as fatigue, weight gain, menstrual irregularities.

- General examination with a special reference to general body built, height, weight, pulse, blood pressure, respiratory rate, pallor, icterus, cyanosis, clubbing, oedema, lymphadenopathy, body temperature, eye signs, hair skin change, basal metabolic rate.

All the system (Cardiovascular System, Respiratory System, CNS System and Abdomen) were examined thoroughly.

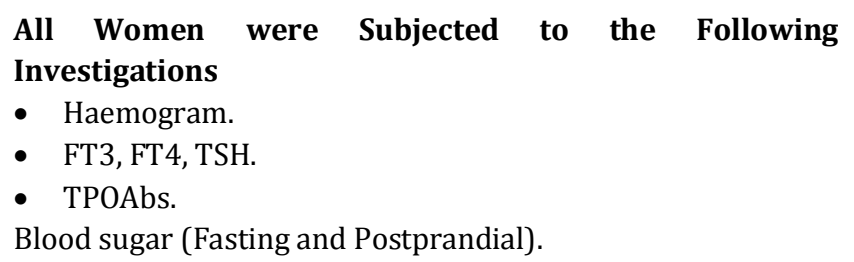

\section{Result and Analysis}

Most of the women were between age group of 20 to 25 years, approximately $45 \%$ of the study group; $25 \%$ of women were between age group 26-30 years; $15 \%$ between age group of $31-35$; and $15 \%$ were between $36-40$ years.

\section{Age Distribution}

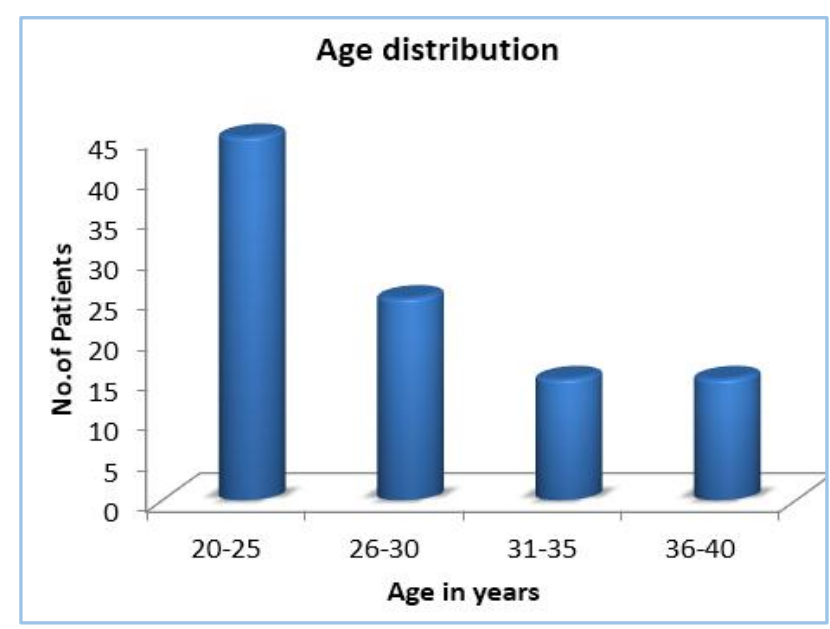

- Most of the women were parity of 33\% (1-2) and 30\% (2-3), 3-4 (25), 4 (12).

- Out of 100 women, 11 women showed postpartum thyroid dysfunction (Approximately 11\%).

- 06 women were hyperthyroid having thyroid value between 21.9-29.0 and TSH between 0.005-0.350.

- 02 women show subclinical hypothyroidism (Normal T3, T4 and high TSH).

- 03 women were hypothyroid (Decreased T3-T4, increased TSH).

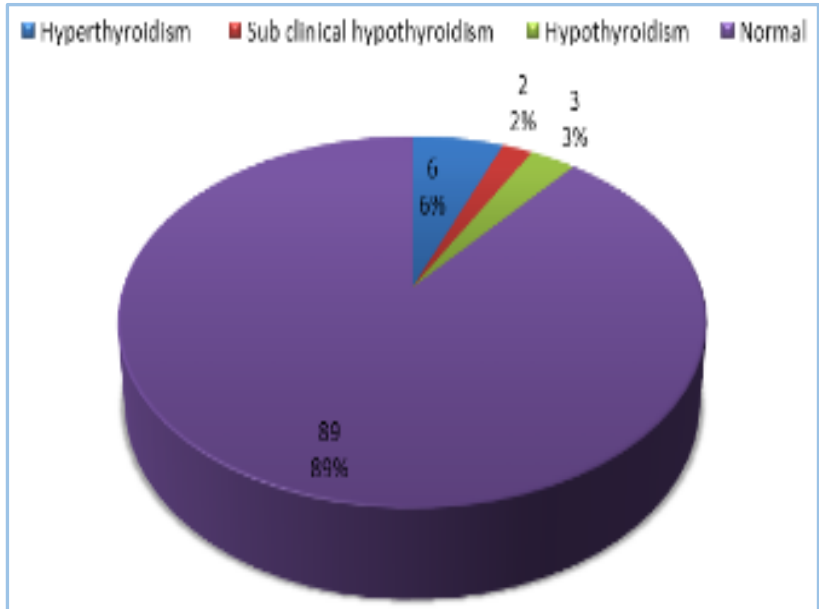

\section{Pie Chart showing Distribution of Thyroid Dysfunction at 6 Weeks}

- All women were followed with OPD, phone and home visit at 6 months.

- Out of 11 women who were previously showing postpartum thyroid dysfunction, two women showed complete recovery.

- Out of 6 hyperthyroid 2 became hypo, 1 became euthyroid and 3 remained hyper at 6 months.

- Out of 5 hypothyroid, 1 became euthyroid, 4 remained hypothyroid.

- Thus at the end of study, approximately $9 \%$ women were having thyroid dysfunction. 


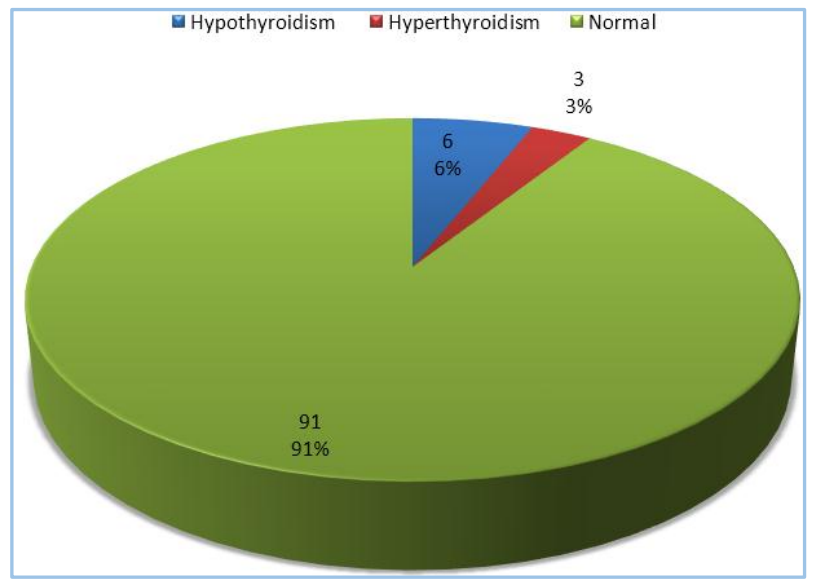

Pie Chart showing Distribution of Thyroid Dysfunction at 6 Months

- In this study 8 women were having positive TPOAb, in which 5 women were showing thyroid dysfunction and 3 women who were positive did not show postpartum thyroid dysfunction.

- Thus in TPOAb positive women, prevalence was app. $62 \%$.

- In this study 4 women were having gestational diabetes, out of which one woman also had postpartum thyroid dysfunction $(25 \%)$.

\begin{tabular}{|c|c|c|c|c|c|c|}
\hline \multirow[t]{2}{*}{ Title } & \multicolumn{3}{|c|}{ At 6 week } & \multicolumn{3}{|c|}{ At 6 month } \\
\hline & & $\%$ & Pvalue & & $\%$ & Pvalue \\
\hline \multirow{2}{*}{ Age(year) } & $20-25$ & 45 & \multirow{4}{*}{$<0.01$} & $20-25$ & 45 & \multirow{4}{*}{$<0.01$} \\
\hline & $26-30$ & 25 & & $26-30$ & 25 & \\
\hline \multirow[t]{2}{*}{ Parity } & $1-2$ & 33 & & $1-2$ & 33 & \\
\hline & $2-3$ & 30 & & $2-3$ & 30 & \\
\hline \multirow[t]{4}{*}{ FT4 (pmol/l) } & $89(10.3-21.9$ & 89 & \multirow{4}{*}{$P<0.001$} & $91(10.3-21.9)$ & 91 & \multirow{4}{*}{$P<0.001$} \\
\hline & $6(21.9-29)$ & 6 & & $3(21.9-29)$ & & \\
\hline & $2(12.9-13.5)$ & 2 & & $6(8-10.3)$ & & \\
\hline & $3(8-10.3)$ & 3 & & & & \\
\hline \multirow[t]{4}{*}{$\mathrm{FT} 3(\mathrm{pg} / \mathrm{ml})$} & $89(2-4.4)$ & 89 & \multirow{4}{*}{$P<0.001$} & $91(2-4.4)$ & & \multirow{4}{*}{$P<0.001$} \\
\hline & $6(4.4-10)$ & 6 & & $3(4.4-12)$ & & \\
\hline & $2(2.3-4.4)$ & 2 & & $6(<2)$ & & \\
\hline & $3(<2)$ & 3 & & & & \\
\hline \multirow[t]{2}{*}{$\mathrm{TSH}(\boldsymbol{\mu I} \mathrm{U} / \mathbf{m l})$} & $89(0.35-5.5)$ & 89 & \multirow{2}{*}{$P<0.001$} & $91(0.35-5.5)$ & & \multirow{2}{*}{$P<0.001$} \\
\hline & $\begin{array}{l}5(5.5-18) \\
6(<0.35)\end{array}$ & $\begin{array}{l}5 \\
6\end{array}$ & & $\begin{array}{c}6(5.5-18.6) \\
3(<0.35)\end{array}$ & $9 \%$ & \\
\hline
\end{tabular}

Table 1: Comparison of Thyroid Profile between 6 weeks and 6 months

\begin{tabular}{|c|c|c|c|c|c|}
\hline TPO Ab & $\begin{array}{l}\text { No. Of } \\
\text { women }\end{array}$ & FT4 & FT3 & TSH & P-Value \\
\hline \multirow{2}{*}{ Positive } & \multirow[b]{2}{*}{8} & $3(21.9-29)$ & $4.0-8.0$ & $0.005-0.350$ & \multirow{5}{*}{$<0.001$} \\
\hline & & $2(8.0-10.3)$ & $0.1-2.0$ & $5.5-18.0$ & \\
\hline \multirow{3}{*}{ Negative } & \multirow{3}{*}{92} & $2(21.9-29)$ & $4.4-8.2$ & $0.005-0.350$ & \\
\hline & & $2(10.3-21.9)$ & $2.0-4.4$ & $5.8-7.0$ & \\
\hline & & $1(6.0)$ & 1.2 & 12.0 & \\
\hline
\end{tabular}

Table 2: Association between TPOAb and Thyroid Dysfunction

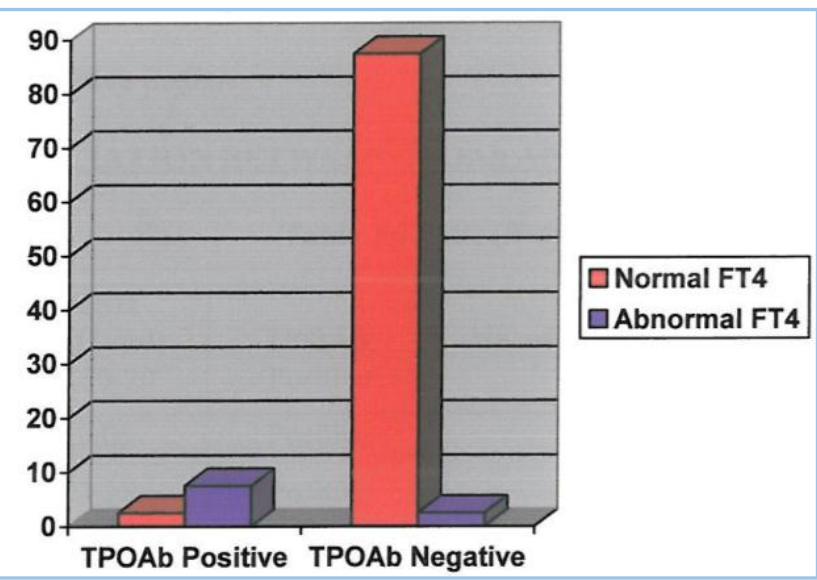

\begin{tabular}{|c|c|c|c|c|}
\hline $\begin{array}{c}\text { No of gestational } \\
\text { diabetes mellitus }\end{array}$ & FT4(pmol/l) & FT3 $(\mathrm{pg} / \mathrm{ml})$ & $\mathrm{TSH}(\mu \mathrm{IU} / \mathrm{ml})$ & $\%$ \\
\hline & $1(29.7)$ & 5.2 & 0.7 & 25 \\
\hline 4.0 & $3(10.3-21.9)$ & $2-4.4$ & $0.35-5.5$ & 75 \\
\hline
\end{tabular}

\section{Table 3: Distribution of Postpartum Thyroid Dysfunction in Gestational Diabetes Mellitus}

\section{DISCUSSION}

Having a baby is one of the wonderful experiences in a woman's life. But some women experience fatigue, lack of sleep anxiety, depression, extreme tiredness, nervousness, not losing weight during their postpartum period. Sometime this occurs due to a new responsibility of a baby, but sometime it is due to a medical condition called as postpartum thyroid dysfunction.(2) Postpartum thyroid dysfunction occurs due to autoimmune inflammation of the thyroid gland.

Pregnancy is a state of immune tolerance, rebound reaction to this pregnancy associated immune suppression. ${ }^{(9)}$ after delivery explains the aggravation of autoimmune syndrome in the puerperal period, e.g. the occurrence of clinically overt postpartum thyroiditis, postpartum thyroid dysfunction classically follows a biphasic course, (Thyrotoxic phase followed by hypothyroid phase).(9)

100 women of postpartum period were randomly selected and were enrolled for study. They were examined and investigated and followed for 6 months. Out of 100 women, 11 women showed postpartum thyroid dysfunction. Out of 11 six women showed hyperthyroid, two showed subclinical hypothyroidism and three were hypothyroid. After 6 months out of 6 hyperthyroid 2 became hypothyroid, 1 became euthyroid and 3 remained hyperthyroid. Out of 5 hypothyroid, 1 became euthyroid, 4 remained hypothyroid. Thus after 6 months, prevalence was $9 \%$. These women were given symptomatic treatment in the form of beta blocker and thyroxin.(10) In my study, all prevalence was $11 \%$ at 6 weeks and $9 \%$ at 6 months.

\section{CONCLUSION}

1. Prevalence of postpartum thyroid dysfunction (Including both hyper and hypothyroidism) is $11 \%$.

2. Prevalence of postpartum thyroid dysfunction in TPOAb positive women was $62 \%$. 
3. Prevalence of postpartum thyroid dysfunction in gestational diabetic mellitus was $25 \%$.

4. $18.1 \%$ women showed recovery in thyroid function after 6 months of postpartum period.

Postpartum thyroiditis is significantly present in women of postpartum period, which usually goes undiagnosed. It shows a strong correlation with TPOab and gestational diabetes mellitus.(7) and depression.(6)

\section{REFERENCES}

1. Parkes AB, Adams $H$, Lazarus JG, et al. Post-partum thyroiditis is a transient autoimmune thyroiditis occurring during the post-partum year. QJM 1996;89(6):429-35.

2. Katherine Pereira, Ann J Brown. Postpartum thyroiditis: not just a worn out mom. journal of Nurse Practitioner 2008;4(3):175-82.

3. Muller AF, Drexhage HA, Berghout A. Postpartum thyroiditis and autoimmune thyroiditis in women of childbearing age: recent insight and consequences for antenatal and postnatal care. Endocr Rev 2001;22(5):605-30.
4. Klein RZ, Haddow JE, Faixt JD, et al. Prevalence of thyroid deficiency in pregnant women. Clin Endoc 1991;35(1):416.

5. www.medscape.com/viewarticle/814179_5 2013;8(6):537-47.

6. Bokhari R, Bhatara VS, Bandettini F, et al. Postpartum psychosis and postpartum thyroiditis. Psychoneuroendocrinology 1998;23(6):643-50.

7. Stagnaro-Green A. Postpartum thyroiditis. Best Practice \& Research clinical Endocrinology \& Metabolism 2004;18(2):303-16.

8. Walfish PG, Meyer J. Determine the prevalence of post partum thyroid dysfunction. Archives on internal medicine 1985;145(2).

9. Premawardhana LDKE, Parkes AB, Lazarus JH. Thyroiditispostpartum in Editor-in-chief: Luciano Martini. Ed. Encyclopedia of endocrine diseases. New York:Elsevier, 2004;pp 509-14.

10. Stagnaro-Green A. Recognizing, understanding, and treating postpartum thyroiditis. Endocrinology \& Metabolism clinics of North America 2000;29(2):417-30. 